\title{
Natural radioactivity of finish and masonry materials
}

\author{
Daria Buzina ${ }^{1, *}$, Igor Engovatov ${ }^{1}$, Dinh Dap Nguyen $^{1}$, and Artur Ovakimyan ${ }^{1}$ \\ ${ }^{1}$ Moscow State University of Civil Engineering, Yaroslavskoe shosse, 26, Moscow, 129337, Russia
}

\begin{abstract}
Research findings of natural radioactivity of materials widely used in industrial and civil construction, are presented. The research is carried out according complex techniques which include measurement and calculation of radiation parameters establishing natural radioactivity of materials - specific radioactivity of $226 \mathrm{Ra}, 232 \mathrm{Th}$, 40K, summarised specific radioactivity, equivalent dose rate and radon flow density. Finish and masonry materials were used as principle objects of the research. The obtained findings allow to make a conclusion that all the studied materials are related to the first class and may be used unrestricted. Comparison with foreign data is provided. Correlation between radiation parameters is established. The data received may be deployed for comparative analysis of the Russian and European approaches to assessment of radiation safety to use the studied types of building materials.
\end{abstract}

\section{Relevance of the research}

One of the key factors determining environmental safety of human's habitat is the radiational one. It takes account of impact of ionising radiation from natural and artificial sources, including, for the account of natural radioactivity of building materials and goods.

Under human's habitat one understands, among others, all the buildings and structures in which the human being spends a considerable part of his life. Natural radioactivity of building materials out of which buildings are made, is determined by natural radionuclides distributed in rocks. Out of them the most important is radioactive series $238 \mathrm{U}$ with daughter products, radioactive series $232 \mathrm{Th}$ with daughter products and potassium -40 $(40 \mathrm{~K})$. Immediately radiation exposure upon the human being (internal and external radiation) is exercised by gamma radiation and by radioactive gas radon. Reduction in radiation component of environmental safety of human's habitat is necessary and is possible for the account of using building materials with the low content of natural radionuclides [1]. Considering a permanently extending product range of building materials being fabricated by manufacturers for consumers, control over safety of such products is actual both for Russia and for foreign countries.

\footnotetext{
* Corresponding author: $\underline{\text { dn89@bk.ru }}$
} 


\section{Research methodology}

Natural radioactivity of building materials was researched with the use of a developed complex computative experimental techniques for determining radiation parameters which establish radiation hazard of building materials:

- assessment of specific activity of ${ }^{226} \mathrm{Ra},{ }^{232} \mathrm{Th},{ }^{40} \mathrm{~K}$ in the samples being studied;

- calculation of effective total activity of natural radionuclides NRN;

- measurements of equivalent dose rate (EDR);

- assessment of radon flow density from material surface;

- calculation of activity concentration index (I).

Specific activity is measured according to standard techniques with the use of scintillation gamma-beta spectrometer MKC-AT1315 under GOST 30108-94.

EDR was measured using dosimeter-radiometer DKC-96 excluding outer radiation background for the account of using lead protection.

Radon flow density (RFD) was measured from the surface of building materials using a passive sorption method with the help of a multifunctional measuring complex for radon monitoring "Camera".

Sample preparation for each type of measurement was carried out individually. For each type of material measurements were carried out at least 5 times. Samples were processed by mathematical statistics method.

Calculation of activity concentration index (I) was performed under techniques as described in the European regulating document [2].

$$
I=C_{R a} / 300 B q^{*} \mathrm{~kg}^{-1}+C_{T h} / 200 B q^{*} \mathrm{~kg}^{-1}+C_{K} / 3000 B q^{*} \mathrm{~kg}^{-1}
$$

where $\mathrm{C}_{\mathrm{Ra}}, \mathrm{C}_{\mathrm{Th}}, \mathrm{C}_{\mathrm{K}}$ are radium, thorium an potassium activity concentrations $\left(\mathrm{Bq} \cdot \mathrm{kg}^{-1}\right)$ in the building material.

Investigations levels can be derived for practical monitoring purposes. Because more than one radionuclide contribute to the dose, it is practical to present investigation levels in the form of an activity concentration index. The activity concentration index should also take into account typical ways an amount in which the material in used in a building.

\section{Objects of research}

Objects of the research are widely used finish and masonry materials:

- ceramic and facade tiles;

- tile adhesive;

- bricks;

- dry mixes and concretes.

No building can be imagined without those materials.

It is worth mentioning that when building residential property, outer building envelopes performed of bricks are preferred; this results in increased interest in radiation characteristics of this building material. As well, one of popular styles in the interior is loft; its characteristic feature is unconditioned brickwork. In such property the main man-made radiation background will be resulted from bricks. Figure 1 shows loft style in interior. 


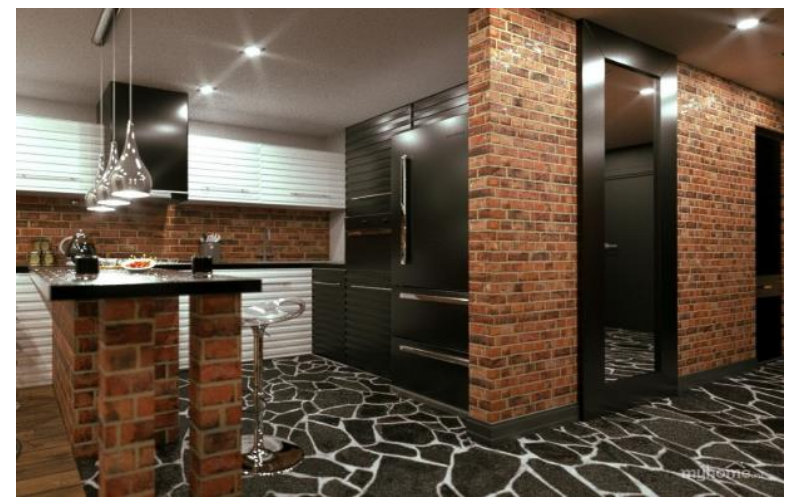

Fig. 1. Loft style in interior

\section{Results}

Results of measurements of natural radionuclides in bricks as well as of equivalent dose rate are shown in Table 1.

Table 1. Averaged values of equivalent dose rate and radon flow density in building materials

\begin{tabular}{|l|c|c|c|c|c|c|c|}
\hline \multicolumn{1}{|c|}{ Building material } & $\begin{array}{c}\mathbf{A}_{\mathbf{R a}}, \\
\mathbf{B q} / \mathbf{k g}\end{array}$ & $\begin{array}{c}\mathbf{A}_{\mathbf{T h}}, \\
\mathbf{B q} / \mathbf{k g}\end{array}$ & $\begin{array}{c}\mathbf{A}_{\mathbf{K}}, \\
\mathbf{B q} / \mathbf{k g}\end{array}$ & $\begin{array}{c}\mathbf{A}_{\text {eff, }} \\
\mathbf{B q} / \mathbf{k g}\end{array}$ & $\begin{array}{c}\mathbf{E D R}, \\
\mathbf{m c S v} / \mathbf{h}\end{array}$ & $\begin{array}{c}\mathbf{R F D ,} \\
\left.\mathbf{m B q} / \mathbf{m}^{\mathbf{2}_{*}} \mathbf{s}\right)\end{array}$ & $\mathbf{I}$ \\
\hline Ceramic tile & 34 & 66 & 291 & 146.5 & 0.21 & 9 & 0.54 \\
\hline Paving flag & 13 & 6 & 127 & 32.5 & 0.17 & 8 & 0.12 \\
\hline Lime-and-sand bricks & 9 & 2 & 30 & 13.8 & 0.16 & 11 & 0.05 \\
\hline Red bricks & 27 & 23 & 367 & 89.9 & 0.23 & 13 & 0.33 \\
\hline Fire-clay bricks & 53 & 67 & 307 & 167.8 & 0.21 & 12 & 0.61 \\
\hline Facade tiling & 7 & 6 & 89 & 22.8 & 0.26 & 6 & 0.08 \\
\hline Universal dry mix & 40 & 9 & 38 & 54.6 & 0.20 & 14 & 0.19 \\
\hline Tile adhesive & 12 & 7 & 21 & 22.2 & 0.17 & 8 & 0.08 \\
\hline $\begin{array}{l}\text { GS-polysterene } \\
\text { concrete }\end{array}$ & 12 & 8 & 161 & 37.2 & 0.17 & 16 & 0.13 \\
\hline $\begin{array}{l}\text { Silicate } \\
\text { tongue\&groove } \\
\text { blocks }\end{array}$ & 10 & 2 & 43 & 15.8 & 0.16 & 11 & 0.06 \\
\hline $\begin{array}{l}\text { Foamed concrete } \\
\text { blocks }\end{array}$ & 20 & 15 & 62 & 45.4 & 0.18 & 21 & 0.16 \\
\hline
\end{tabular}

Table 2 provides values of radiation characteristics from published data on building materials in Russia and in other countries [3-6]. 
Table 2. Natural radioactivity of building materials in Russia and in other countries

\begin{tabular}{|c|l|c|c|c|c|c|}
\hline $\begin{array}{c}\text { Building } \\
\text { material }\end{array}$ & $\begin{array}{c}\text { Manufacturer } \\
\text { country }\end{array}$ & $\begin{array}{c}\mathbf{A}_{\mathbf{R a}}, \\
\mathbf{B q} / \mathbf{k g}\end{array}$ & $\begin{array}{c}\mathbf{A}_{\text {Th }}, \\
\mathbf{B q} / \mathbf{k g}\end{array}$ & $\begin{array}{c}\mathbf{A}_{\mathbf{K}}, \\
\mathbf{B q} / \mathbf{k g}\end{array}$ & $\begin{array}{c}\mathbf{A}_{\text {eff, }} \\
\mathbf{B q} / \mathbf{k g}\end{array}$ & $\mathbf{I}$ \\
\hline \multirow{4}{*}{ Red bricks } & Russia & 40 & 41 & 604 & 147 & 0.54 \\
\cline { 2 - 7 } & Spain & 68 & 56 & 416 & 178 & 0.65 \\
\cline { 2 - 7 } & Finland & 80 & 62 & 986 & 249 & 0.91 \\
\cline { 2 - 7 } & Vietnam & 11 & 60 & 43 & 92 & 0.35 \\
\hline \multirow{5}{*}{ Brown bricks } & Russia & 59 & 67 & 670 & 206 & 0.76 \\
\cline { 2 - 7 } & Germany & 44 & 59 & 404 & 157 & 0.58 \\
\cline { 2 - 7 } & Canada & 32 & 31 & 488 & 116 & 0.42 \\
\cline { 2 - 7 } & Malaysia & 38 & 21 & 234 & 86 & 0.31 \\
\hline \multirow{5}{*}{ Dry mixes } & Russia & 30 & 43 & 77 & 92 & 0.34 \\
\cline { 2 - 7 } & Egypt & 40 & 26 & 244 & 96 & 0.34 \\
\cline { 2 - 7 } & Vietnam & 34 & 30 & 570 & 124 & 0.45 \\
\cline { 2 - 7 } & Saudia Arabia & 144 & 52 & 303 & 239 & 0.84 \\
\hline \multirow{5}{*}{ Ceramic tile } & Russia & 61 & 66 & 476 & 190 & 0.69 \\
\cline { 2 - 7 } & Canada & 66 & 46 & 925 & 209 & 0.76 \\
\cline { 2 - 7 } & India & 95 & 75 & 659 & 252 & 0.91 \\
\cline { 2 - 7 } & Vietnam & & & & & 0.80 \\
\hline
\end{tabular}

Materials should be exempted from all controls concerning their radioactivity if it is shown that the dose criterion for exemption is not exceeded. This can be done by comparing results of activity concentration measurements with the activity concentration index, or as appropriate, by means of a material-specific dose assessment. An exempted material should be allowed to enter the market (including import and export within the EU) and to be used for building purposes without any restrictions related to its radioactivity. In the case of export within the EU, it is understood that the value of the activity concentration index or a declaration of exemption should be included in the technical specifications of the material.

Some traditionally used natural building materials contain natural radionuclides at levels such that the annual dose of $1 \mathrm{mSv}$ might be exceeded. Some of such materials may have been used already for decades or centuries. In these cases, the detriments and costs of giving up the use of such materials should be analysed and should include financial and social costs.

\section{Conclusion}

The considered tables of building materials are related to the first class under the Russian law [7]. Out of the samples experimentally studied by authors, greatest values are found with masonry materials - fire-clay bricks.

Correlation dependence between the content of natural radionuclides and equivalent dose rate is observed: the higher the value of specific effective activity is, the bigger the dose rate is.

Univocal dependence between the criteria of natural radioactivity and radon flow density is not discovered; this is related to low values of flow density; they are hard to 
establish using the available equipment. Nevertheless, so far as inert radioactive gas radon$222\left({ }^{222} \mathrm{Rn}\right)$ establishes person's internal radiation, the measurement techniques must be improved.

According to published data of different countries, values of specific activity of building materials are sufficiently high, however, they are permitted for construction of buildings and structures both under the Russian approach and under that European. In the case with tiling in Vietnam and with red bricks of Finland the activity concentration index takes on threshold values; and effective specific activity is far from the upper threshold. This discrepancy and incompliances as discovered within the process of work [6], evidences discrepancy of Russian and European norms. What is permitted for the use unrestricted in Russia, is applied only with restrictions in the European community.

\section{References}

1. Lars-Erik Holm, ICRP Publication 103, 37, 2-4 (2007)

2. EC, Directorate-General Environment, Nuclear Safety and Civil Protection, Radiation protection Principles concerning the Natural Radioactivity of Building Materials. (1999)

3. N.S. Le, T.B. Nguyen, Y. Truong, T.N. Nguyen, T.L. Nguyen, V.P. Nguyen, D.T. Nguyen, K.T. Nguyen, D.K. Tran, Conf. WM2011, 11255 (2011)

4. S. Pavlidou, A. Koroneos, C. Papastefanou, G. Christofides, S. Stoulos, M. Vavelides, Bul. of the Geol. Soc. of Gr., 19, 113-120 (2004)

5. EL-Taher, J. Phys., 57 (3-4), 726-735 (2012)

6. D. Buzina, I. Engovatov, L. Alimov, M. Slesarev, MATEC Web of Conf., 86, 04044, (2016)

7. SanPiN 2.6.1.2523-09 (NRB-99/2009) (2009) 